\title{
Effects of several extinction treatments upon the integrity of Pavlovian stimulus-outcome associations
}

\author{
ANDREW R. DELAMATER \\ University of Pennsylvania, Philadelphia, Pennsylvania
}

\begin{abstract}
Pavlovian-to-instrumental transfer tests were used to assess the sensitivity of Pavlovian stimulusoutcome (S-O) associations to various extinction treatments in four appetitive conditioning experiments with rats. In Experiment 1, simple nonreinforcement of a stimulus was shown to have little impact on the ability of that stimulus to display outcome-specific transfer of control. Extinguishing a stimulus by pairing the stimulus with an alternative reinforcement in Experiment 2 also had no detectable effect on the $\mathrm{S}-\mathrm{O}$ associations as assessed with the outcome-specific transfer measure. The third and fourth experiments, respectively, examined the impact of postconditioning exposures to random and explicitly unpaired S-O contingencies upon previously learned S-O associations. These treatments, as well, had no detectable harmful effects upon the integrity of the $\mathrm{S}-\mathrm{O}$ associations. In contrast to the consistent failures of various extinction treatments to influence the ability of stimuli to display outcome-specific transfer, these treatments often did reduce the strength of conditioned responding initially trained to these stimuli. These results support the view that extinction entails the preservation of S-O associations as well as the parallel development of inhibitory stimulus-response associations. Other notions of extinction are also discussed.
\end{abstract}

Current research in associative learning has focused on questions related to the content of associations. One kind of question that has received a considerable amount of attention is the extent to which specific attributes of a reinforcer enters into the associative structure. For example, associations between a stimulus and the specific sensory components of a reinforcer have been observed to occur in both Pavlovian (for a review, see Delamater \& LoLordo, 1991) and instrumental conditioning settings (e.g., Colwill \& Rescorla, 1988).

One technique that has been especially useful at assessing the learning of specific stimulus-outcome associations is the transfer test. This test assesses the ability of a stimulus to transfer preferentially its control to new instrumental responses with which it shares an outcome. In Colwill and Rescorla's (1988) experiment, for example, two different instrumental discriminative stimuli were trained initially to indicate when a single instrumental response would be rewarded with different outcomes. Independently, each of those two different outcomes was also earned by different instrumental responses. In an extinc-

The research reported here was performed while the author was a postdoctoral fellow at the University of Pennsylvania. This research was supported through an NSF grant (BNS-88-03514) awarded to R. A. Rescorla, and through an NRSA postdoctoral fellowship (MH10007) awarded to the author. R. A. Rescorla's helpful comments on previous versions of this manuscript and also his enthusiasm and intellect throughout the course of this research are gratefully acknowledged. Reprint requests may be directed to the author, who is presently at the Psychology Department, Brooklyn College-CUNY, 2900 Bedford Ave., Brooklyn, NY 11210 (e-mail: andrewd@jamesl.brooklyn. cuny.edu). tion test involving a choice between the two additional instrumental responses, it was observed that the discriminative stimuli were more successful at transferring their control to the responses with which they shared an outcome. This result can be taken to mean that the associative structures coding both stimulus-outcome (S-O) and response-outcome $(\mathrm{R}-\mathrm{O})$ relations represent some of the specific sensory features that differentiate the two reinforcers.

The usefulness of this test in studying outcome-specific associations can be seen by the rather extensive analysis of the associative structure of instrumental learning carried out recently by Rescorla (e.g., 1991, 1992a, 1992b) and Colwill (e.g., 1993, 1994). One of the noteworthy features of this analysis has been the observation that associations with the outcome are extremely resistant to various manipulations designed to undermine those associations. For example, Rescorla (1991) used transfer tests to demonstrate that instrumentally trained $\mathrm{R}-\mathrm{O}$ associations are highly insensitive to simple extinction procedures. This was true even in circumstances in which nonreinforcement of the response occurred at a time when an alternative outcome was presented in place of the original outcome. In addition, Rescorla (1992b) observed that specific $\mathrm{R}-\mathrm{O}$ associations survived a postconditioning treatment in which the $\mathrm{R}-\mathrm{O}$ relation had been randomized by the delivery of response-independent outcomes. These results are important because they help to characterize the relationship between specific associative structures and changes in environmental contingencies.

Rescorla (1992a) extended this analysis to the question of whether $\mathrm{S}-\mathrm{O}$ associations established by instrumental 
discrimination training would also be insensitive to the effects of various extinction manipulations. Indeed, some of the results reported earlier for $\mathrm{R}-\mathrm{O}$ associations were paralleled in the examination of $\mathrm{S}-\mathrm{O}$ associations. In particular, Rescorla observed that $\mathrm{S}-\mathrm{O}$ associations established by instrumental training were also immune to the effects of both nonreinforcement as well as pairings with an alternative reinforcement. The extinction treatment in these studies was not without any lasting effect on performance, however. In spite of the immunity of the $\mathrm{S}-\mathrm{O}$ associations to extinction as revealed in the transfer tests, the stimuli had lost their ability to control the instrumental response with which they were originally trained. This result can be interpreted as reflecting the parallel development over the course of an extinction treatment of inhibitory S-R associations (Rescorla, 1993).

A comparable analysis of the associative structures of Pavlovian conditioning has not yet been performed. There have been, however, several reports of the use of the instrumental transfer test to document the learning of specific S-O associations in Pavlovian paradigms (e.g., Colwill \& Rescorla, 1988; Delamater, 1995; Kruse, Overmier, Konz, \& Rokke, 1983). These reports encourage the use of the transfer test to examine the sensitivity of $\mathrm{S}-\mathrm{O}$ associations established through Pavlovian conditioning to various changes in environmental contingencies. The present report can be seen as one such attempt.

A Pavlovian appetitive conditioning paradigm with rats (Farwell \& Ayres, 1979; Holland, 1979) was used in the studies reported here. The first experiment explored the impact of a simple extinction treatment on the prior learning of specific $\mathrm{S}-\mathrm{O}$ associations. The second experiment examined whether training with an alternative outcome might be a successful extinction procedure. The third and fourth experiments, respectively, examined the sensitivity of Pavlovian $\mathrm{S}-\mathrm{O}$ associations to postconditioning random CS-US and negative CS-US contingency treatments. In all of these studies, the sensitivity of Pavlovian S-O associations to these manipulations was measured with the instrumental transfer test. In general, as Rescorla observed in instrumental settings, the Pavlovian $\mathrm{S}-\mathrm{O}$ associations studied here were shown to be highly insensitive to manipulations designed to undermine those associations.

\section{EXPERIMENT 1}

The aim of the first experiment was to examine outcomeselective transfer of Pavlovian stimuli to instrumental responding after one of those stimuli had undergone a simple extinction treatment. Initially, all rats were given Pavlovian differential outcome training, that is, stimulus A signaled the occurrence of one type of food $(A+)$ and stimulus $B$ signaled the occurrence of a second type of food $\left(\mathrm{B}^{*}\right)$. Subsequently, one of these stimuli was extinguished while the other was not presented (e.g., A-). Finally, both $A$ and $B$ were tested for their ability to transfer to independently trained instrumental responses. If
Pavlovian $\mathrm{S}-\mathrm{O}$ associations are immune to the effects of extinction, then both stimuli would be expected to transfer equally.

\section{Method}

\section{Subjects}

Thirty-two male Sprague-Dawley rats, weighing $387-484 \mathrm{~g}$ at the beginning of the experiment, were used. They were individually housed in a colony room that was on a 16 -h-light/8-h-dark cycle, and they were maintained at $80 \%$ of their ad-lib body weights with daily supplemental feedings of Purina Lab Chow

\section{Apparatus}

The apparatus consisted of eight identical standard operant chambers, each of which was housed inside a sound- and light-resistant shell. The operant chambers measured $22.9 \times 20.3 \times 20.3 \mathrm{~cm}$. Two end walls were constructed of aluminum, and the side walls as well as the ceiling were made from clear Plexiglas. The floor consisted of $0.48-\mathrm{cm}$ stainless steel rods spaced $1.9 \mathrm{~cm}$ apart. Centered on one end wall $10 \mathrm{~mm}$ above the grid floor was a recessed magazine measuring $30 \times 36 \times 20 \mathrm{~mm}$ (length $\times$ width $\times$ depth). A single 45-mg pellet (P. J. Noyes Co., Formula A) was dropped onto the magazine floor when this reinforcer was scheduled, and $.3 \mathrm{ml}$ of an $8 \%$ sucrose solution was delivered through a gravity feed valve into a small well, the top of which was level with the magazine floor, when this reinforcer was scheduled. On the inner walls of the recessed magazine were an infrared detector and emitter enabling the automatic recording of head movements inside the magazine. To the left of the magazine was located a lever, and to the right, through a hole in the ceiling, was suspended a chain that was connected to a microswitch. When not used, the lever was covered with a metal shield and the chain was withdrawn from the chamber. Located above the chamber and attached to the back wall of the outer shell was a speaker, through which a white-noise conditioned stimulus was presented. This noise stimulus measured approximately $76 \mathrm{~dB}$ re $20 \mu \mathrm{N} / \mathrm{m}^{2}$ against a background level of $62 \mathrm{~dB}$. Next to the speaker was located a 6W light bulb. The chamber was always dark except when the visual conditioned stimulus was presented. Fans attached to the outer shells provided for cross-ventilation within the shell as well as background noise. All experimental events were controlled and recorded automatically by a microcomputer and interfacing equipment located in an adjacent room.

\section{Procedure}

Initially the rats were given one magazine training session with each reinforcer. Each of these sessions lasted $20 \mathrm{~min}$, during which the reinforcer was randomly presented 20 times.

Instrumental training. Following magazine training, each rat was instrumentally conditioned with the lever and chain. Initially, the rats were taught, using a continuous reinforcement schedule, to leverpress for one outcome (pellets or sucrose) until approximately 70 reinforcements were earned. Then, in a separate session, they were taught to chainpull for the other outcome (sucrose or pellets). The particular $\mathrm{R}-\mathrm{O}$ relations were counterbalanced across subjects. There then followed 8 days of instrumental training with a random-interval (RI) 60 -sec schedule of reinforcement in effect. There were two 20-min sessions each day separated by approximately $30 \mathrm{~min}$. During one session, the lever was the only response manipulandum present; during the other, the chain was the only response manipulandum present. The order of training with the lever and chain each day was balanced across days.

Pavlovian acquisition. A Pavlovian conditioning procedure was implemented over the next 15 consecutive daily sessions. Each 40-min session contained four 30-sec presentations of the noise $(\mathrm{N})$ and four 30 -sec presentations of the light $(\mathrm{L})$ stimuli. 
Each of the four $\mathrm{N}$ and $\mathrm{L}$ trials ended in reinforcement. For half of the subjects, sucrose served as the unconditioned stimulus (US) on $N$ trials and pellets, as the US on $L$ trials; the other rats received the reverse stimulus-reinforcer relations. These stimulus-reinforcer relations were made orthogonal to the earlier trained instrumental (leverpress and chainpull) response-reinforcer relations. The intertrial interval (ITI), measured from stimulus offset to the next onset, averaged $4.5 \mathrm{~min}$. Four event sequences differing in terms of the order of $\mathrm{N}$ and L trials and the specific ITI values were repeated irregularly across training.

Pavlovian extinction. Following the acquisition phase, one of the stimuli was extinguished over 10 consecutive daily sessions. These extinction sessions were similar to the acquisition sessions, with the exception that no USs were presented. There were a total of 8 extinction trials in each of these sessions. The nonextinguished stimulus was not presented during this phase. The identity of the extinguished stimulus, $N$ or $L$, was counterbalanced across animals. In addition, the extinguished stimulus was selected to be orthogonally related to the particular instrumental R-O and Pavlovian $\mathrm{S}-\mathrm{O}$ relations that already had been trained.

Instrumental transfer tests. One transfer test was administered following the Pavlovian extinction phase. For the purposes of this test, all subjects received two additional daily sessions of instrumental training with each response trained separately. Then, to familiarize the rats with an instrumental choice procedure, they were given one 8-min extinction session during which both the lever and chain manipulanda were present. This response training occurred over a 3-day period beginning on the day following the final extinction session.

The transfer test occurred on the next day. There were four trials of $\mathrm{N}$ and four trials of $\mathrm{L}$ during this 16-min test session. The ITI, defined from stimulus offset to onset, was fixed at $90 \mathrm{sec}$ during this test session. The order of stimulus presentations was NLNLLNLN.

Statistical analysis. Analysis of variance (ANOVA) techniques as suggested by Kirk (1968) were used here and throughout the manuscript to statistically evaluate the data. A Type I error rate of .05 was used in all analyses. Where appropriate, the post hoc method of Newman-Keuls was used to evaluate paired comparisons.

\section{Results and Discussion}

Acquisition of conditioned magazine-approach responding proceeded smoothly over the course of train- ing, as can be seen in Figure 1. The figure portrays mean magazine response rate in the presence of the stimuli (collapsed across all counterbalancing conditions), as well as during a $30-\mathrm{sec}$ prestimulus period. In addition, the Phase 2 extinction data are shown for the stimulus subsequently undergoing extinction. By the final acquisition session, the stimuli evoked more magazine responses than had occurred in the prestimulus period. Compared with the final acquisition session, extinction resulted in a rapid loss in stimulus-evoked magazine responses on the first session $[F(1,31)=47.11]$. Conditioned responding underwent a further decline from the first extinction to the final extinction session $[F(1,31)=66.79]$.

The data of greatest interest are from the transfer test, portrayed in Figure 2. The mean rate of instrumental responses during the choice test is broken down in terms of whether the particular response had been reinforced earlier with an outcome that was the same as or different from that paired with the Pavlovian test stimulus. Pretrial responses are also displayed. Data are shown separately for the nonextinguished and extinguished stimuli, collapsing across stimulus and instrumental response identity. More "same-outcome" than "different-outcome" responses indicate selective transfer based on shared reinforcers. The first point to note from these data is that the nonextinguished stimulus was effective at showing outcomespecific transfer, and that this transfer appeared to have arisen from an increase in same-outcome responding relative to the pretrial rate. The observation of a difference between same- and different-outcome responding is consistent with results reported elsewhere, although that effect sometimes arises from an increase in same-outcome responding and sometimes as a decrease in differentoutcome responding relative to the pretrial rates (e.g., see Colwill \& Rescorla, 1988). The second point to note is that the extinguished and nonextinguished stimuli displayed similar amounts of selective transfer. This obser-

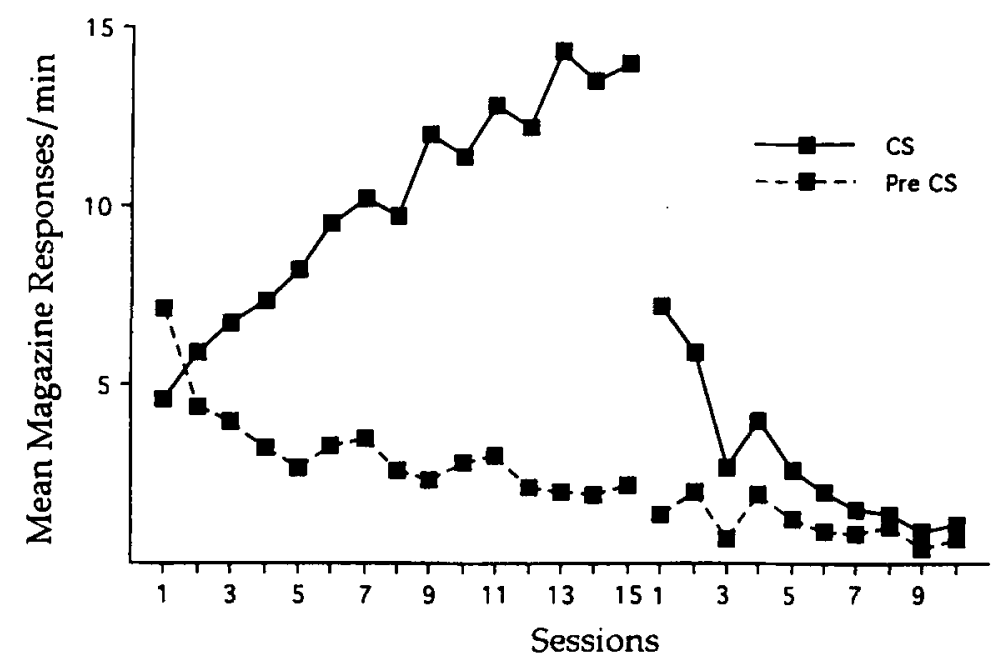

Figure 1. Mean magazine responses per minute during and prior to the 30 -sec CSs (combined) over the 15 sessions of acquisition and over the 10 sessions of extinction for the CS undergoing extinction. 


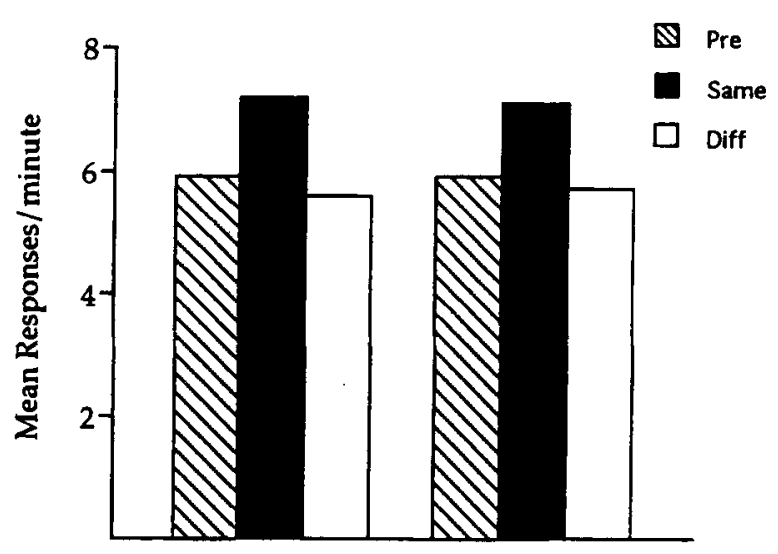

No Extinction Extinction

Figure 2. Mean instrumental responses per minute during the transfer test of Experiment 1 for the same-outcome and differentoutcome responses in the presence of and prior to the stimulus that had been extinguished or not.

vation suggests that the simple extinction treatment had little effect upon the $\mathrm{S}-\mathrm{O}$ association.

A two-way repeated measures ANOVA was used to analyze these data. For the purposes of this analysis, since there were no differences between pretrial same-outcome and pretrial different-outcome responses, these have been pooled to create one pretrial score for each stimulus. The analysis revealed only the main effect of trial type to be reliable $[F(2,62)=8.67]$. To evaluate the source of this effect, Newman-Keuls post hoc tests evaluated each of the three paired comparisons between the pretrial, same-outcome, and different-outcome scores for each group. This analysis revealed that for each stimulus, sameoutcome responding was greater than both differentoutcome responding and pretrial responding.

An additional analysis was performed on magazineapproach response data collected during the transfer test. In this test, significantly more magazine responses occurred in the presence of the nonextinguished stimulus ( 8.2 responses per minute) than occurred in the presence of the extinguished stimulus (6.2 responses per minute) $[F(1,31)=5.05]$. Unfortunately, prestimulus magazine responding was not recorded during this test session. Thus, it is not possible to determine whether the responding shown to the extinguished stimulus reflects a recovery of conditioned responding during the test.

The transfer data from the present study are clear in supporting the conclusion that Pavlovian conditioned stimuli paired with different outcomes have acquired associations with detailed features of those outcomes. Furthermore, the data provide some initial indication that Pavlovian S-O associations are immune to the effects of a simple extinction treatment. This conclusion agrees well with that reached by Rescorla in his assessment of the effects of extinction on $\mathrm{S}-\mathrm{O}$ associations arising from instrumental training.
However, it is noteworthy that extinction was not without an effect on some aspect of the association in the present experiment. Conditioned magazine responses during the transfer test had been weakened by extinction. At the very least, this result suggests that a null effect with the transfer measure is not to be attributed to a total failure of the effects of extinction to generalize to a somewhat different test situation (e.g., Bouton \& Bolles, 1979). Moreover, precisely this pattern of results has been observed in the context of instrumental conditioning studies using the transfer test to explore the effects of extinction. Recall that in those investigations, although extinction eliminated the ability of a stimulus to control the instrumental response with which it had been trained, it did not reduce its ability to transfer its control to new responses with which it shared an outcome. These differing effects of extinction on transfer responses and initially trained responses have been interpreted in terms of the development of inhibitory S-R associations during extinction (e.g., Rescorla, 1993). Perhaps Pavlovian stimuli undergoing extinction similarly develop inhibitory associations with their own conditioned responses.

\section{EXPERIMENT 2}

The previous experiment explored the effect of simple nonreinforcement upon the prior learning of $\mathrm{S}-\mathrm{O}$ associations established by Pavlovian training. The present experiment examined the effect upon these $\mathrm{S}-\mathrm{O}$ associations of reinforcement with an alternative outcome to that used to establish the original $\mathrm{S}-\mathrm{O}$ associations (see also Bouton \& Peck, 1992; Peck \& Bouton, 1990). Rescorla (1991, 1992a) noted the conceptual similarity between these two procedures. Both simple nonreinforcement and reinforcement with an alternative outcome involve the omission of the specific outcome used originally. Conversely, if nonreinforcement were to be regarded as an outcome of a sort, then both procedures involve pairing the stimulus with alternative outcomes after original training. One potentially important difference between the two procedures is that one of these alternative outcomes is a reinforcing outcome and the other is not. Thus, reinforcement of a stimulus with an alternative outcome might be regarded as a more powerful extinction treatment than nonreinforcement alone, since it guarantees that subjects are, to some extent, processing the stimuli at a time when the original outcomes are being omitted (see Robbins, 1990).

Experiment 2 examined this possibility using a betweengroups experimental design. One group of rats initially received Pavlovian differential outcome training $(\mathrm{A}+$ and $\mathrm{B}^{*}$ ), as in the previous experiment. Subsequently, the differential $\mathrm{S}-\mathrm{O}$ associations were extinguished in this group by pairing the stimuli with a common alternative outcome (A\# and B\#) in Phase 2. The effect of this training with a common alternative outcome upon the original $\mathrm{A}+$ and $\mathrm{B}^{*}$ associations was then assessed using the instrumental transfer test. A second group of rats received identical training in two successive phases, except that 
the order of the two training phases was reversed. The first group received nonreinforcement of the differential outcomes during their second-phase training with an alternative outcome, whereas the second group never received nonreinforcement of their differential outcomes at a time when those outcomes were expected. Thus, to the extent that pairing a stimulus with an alternative outcome is an especially effective extinction treatment, we should expect the order in which differential $\mathrm{S}-\mathrm{O}$ associations are acquired to be important.

\section{Method}

\section{Subjects and Apparatus}

A new set of 16 male Sprague-Dawley rats, weighing 444 $609 \mathrm{~g}$ at the beginning of the experiment, were used. They were individually housed and maintained as in the previous experiment. The apparatus was the same as that used in the previous experiment.

\section{Procedure}

The procedures used in the present study were in most respects similar to those used in the previous experiment, except as noted below. After initial magazine and instrumental response training (which occursed over six sessions), the rats were segregated into two groups. The rats in Group Extinction initially received 15 consecutive Pavlovian differential outcome training sessions as in the previous experiment. In the second phase of Pavlovian training, each stimulus was reinforced with a common outcome that differed from the outcomes used earlier, that is, with a $15 \%$ polycose solution delivered to a second well that was located $2 \mathrm{~mm}$ next to the sucrose well. This phase also continued for 15 consecutive sessions, with the parameters being the same as those used in the first phase. The second group of rats, Group No Extinction, was given training over two successive phases that was identical to that received by Group Extinction except that the order in which their two training phases occurred was reversed. Thus, both groups received the same pairings of the stimuli with multiple outcomes. Only Group Extinction, however, received nonreinforcement of their differential outcomes at a time when those outcomes were expected.
As in the previous experiment, the particular $\mathrm{S}-\mathrm{O}$ relations were fully counterbalanced within and between groups. They were also orthogonal with respect to the instrumental $\mathrm{R}-\mathrm{O}$ relations.

A somewhat different transfer testing method was adopted in the present experiment. Following Pavlovian training, the rats were again given two additional instrumental training sessions with each response prior to transfer testing. The first transfer test then occurred on the next day. In this test session, 16 trials of each type were given (instead of 4 as in the previous experiment). In addition, only $30 \mathrm{sec}$ separated each trial (instead of $90 \mathrm{sec}$ as in the previous experiments). A second transfer test, identical to the first, was then given after two more instrumental training sessions. In each test session, the order of stimulus trials was as follows: NLLNLNNL NNLLNLNL NNLLNLNL LNNLNLLN. The present test procedures were adopted because it was thought that more test trials with less time between trials would have the effect of diminishing the variability in the data and thereby increase its sensitivity.

\section{Results and Discussion}

Acquisition of conditioned magazine responding in Groups Extinction and No Extinction is portrayed on the left side of Figure 3. Data from the second Pavlovian training phase are portrayed on the right side of Figure 3. During each phase, the group receiving training with differential outcomes (pellets and sucrose) responded more than the group receiving training with the common outcome (polycose). The data from the final block of sessions from each phase were analyzed using a split-plot ANOVA which treated group and phase as factors. The analysis revealed no group or phase main effects $[F \mathrm{~s}(1,14)<1.85]$ but did reveal a significant group $\times$ phase interaction $[F(1,14)=14.57]$. A comparable analysis on the pretrial magazine response data indicated no between-group differences but did show that responding was generally lower than during the stimuli. Mean pretrial response rates at the end of Phase 1 and Phase 2 were, respectively, 3.0

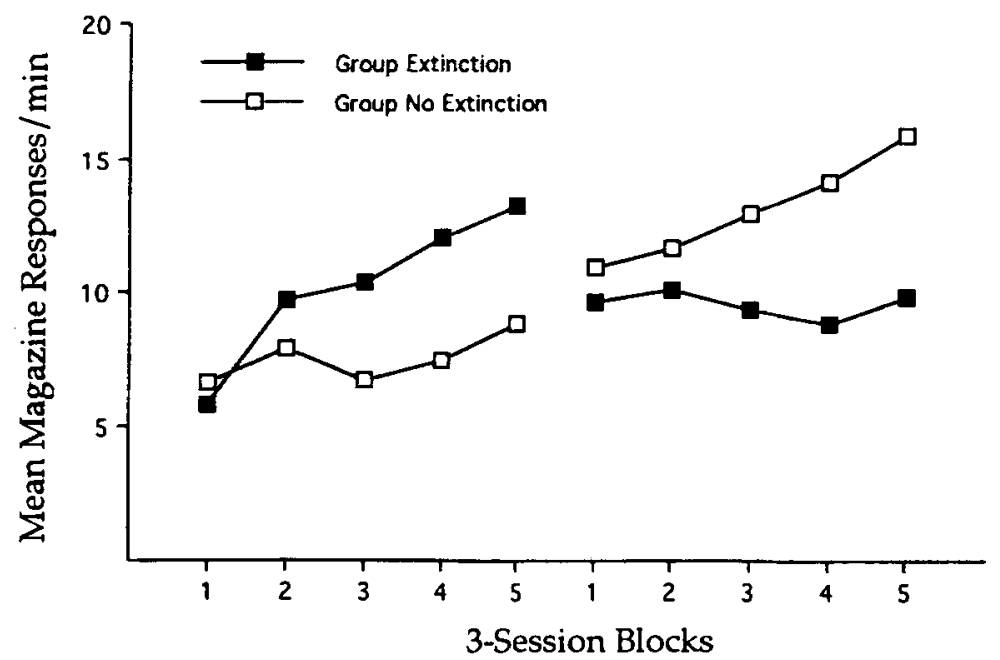

Figure 3. Mean magazine responses per minute in the presence of the CSs over successive three-session blocks in each of the Pavlovian conditioning phases of Experiment 2. In Group Extinction, the two CSs were differentially reinforced in Phase 1 and were trained with a common alternative outcome in Phase 2. In Group No Extinction the order of training was reversed. 
and 2.1 responses per minute for Group Extinction and 2.3 and 3.0 responses per minute for Group No Extinction.

The data of greatest interest are from the transfer tests, which have been pooled and are portrayed in Figure 4. These data show that outcome-selective transfer was not affected by the order in which training with differential and common outcomes occurred. The two groups displayed equivalent amounts of selective transfer of stimulus control. In a split-plot ANOVA, only the trial type main effect was reliable $[F(2,28)=11.18]$. NewmanKeuls post hoc tests revealed that same-outcome responding was greater than different-outcome responding in both groups. However, same-outcome responding was also greater than pretrial responding, but only in Group Extinction. Although pretrial responding numerically fell in between same-outcome and different-outcome responding in Group No Extinction, the apparent differences fell short of significance. Similarly, although Group No Extinction displayed a tendency to respond more overall than Group Extinction, this did not approach statistical reliability.

An additional analysis was performed on the magazineapproach response data collected during the transfer tests. In these tests, the stimuli evoked significantly more magazine responses than did the prestimulus periods $[F(1,14)=17.32]$, but this effect did not interact with group. In other words, the differences in magazine responding seen during the acquisition and extinction phases were not also observed in the transfer test. The mean magazine responses per minute occurring in the stimulus and prestimulus periods for Group Extinction and Group No Extinction, respectively, were 8.2 versus 6.9 responses per minute and 9.0 versus 7.6 responses per minute.

The data from the present experiment are consistent with those reported in the first experiment in showing no impact of an extinction treatment on expression of differential $\mathrm{S}-\mathrm{O}$ associations. The results from the present ex-

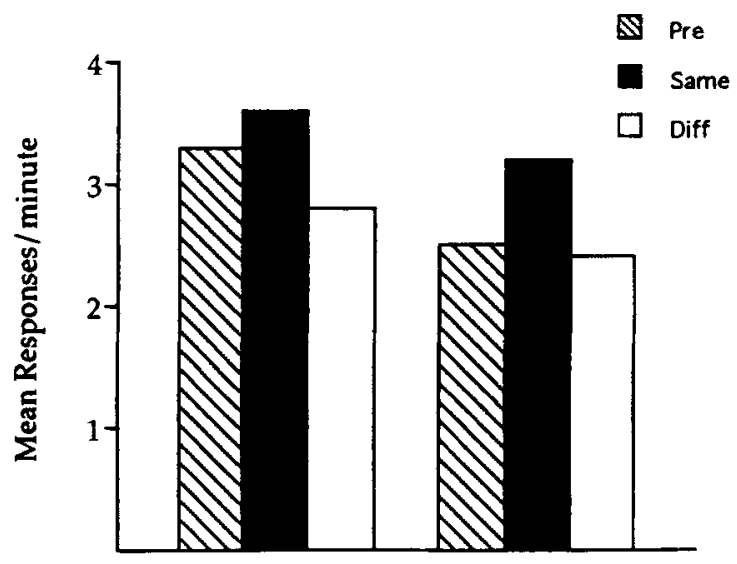

Gp No Extinction Gp Extinction

Figure 4. Mean instrumental responses per minute in the presence of and prior to the CSs during the transfer tests of Experiment 2 for the groups given extinction and no extinction. periment extend the earlier results by showing the failure of an effect of nonreinforcement at a time when the processing of the conditioned stimuli was to some extent being maintained through pairings with an alternative outcome.

This conclusion should be qualified, however, by noting the possibility that training with a common alternative reinforcement did degrade the differential $\mathrm{S}-\mathrm{O}$ associations in Group Extinction, but to a level comparable to that observed in Group No Extinction. It seems possible that training with a common outcome after differential $\mathrm{S}-\mathrm{O}$ learning might produce a degree of retroactive interference (e.g., extinction) that happens to equal the amount of proactive interference (e.g., latent inhibition) shown when training with a common outcome precedes differential $\mathrm{S}-\mathrm{O}$ learning. Although the magazine data from the Pavlovian training phases provided no real suggestion that latent inhibition might have occurred in Group No Extinction, this possibility cannot be dismissed. Note that latent inhibition would have been implicated had the between-group difference in magazine responding seen in Phase 2 of Pavlovian training been smaller than it was in Phase 1. Nevertheless, perhaps the most conservative conclusion that follows from the present experiment is that the expression of associations learned first and second are equally strong.

\section{EXPERIMENT 3}

The previous experiments demonstrated a strong resistance of $\mathrm{S}-\mathrm{O}$ associations to the effects of nonreinforcement. The present experiment examined the effects of another treatment which might be supposed to result in at least partial extinction of $\mathrm{S}-\mathrm{O}$ associations. Rescorla (1967) suggested that a random CS-US contingency treatment should produce a stimulus that is close to associative neutrality. Indeed, several conditioning models assert that exposure to such a procedure should severely degrade previously established conditioned responding (e.g., Gibbon \& Balsam, 1981; Rescorla \& Wagner, 1972).

When the effects of postconditioning exposure to a random CS-US contingency have been explored, transient decremental effects on performance have often been observed (e.g., Lindblom \& Jenkins, 1981). The substantial recovery of conditioned performance observed in this situation has led several authors to conclude that relatively little, if any, associative loss occurs when a random CS-US contingency procedure is used to extinguish conditioned responding (Durlach, 1986; Lindblom \& Jenkins, 1981; Rescorla, 1989). At present, however, little is known about the effects of a postconditioning randomcontingency treatment upon the learning of specific $\mathrm{S}-\mathrm{O}$ associations as revealed in transfer tests like those used in the present studies. One advantage of using this technique to explore the effects of postconditioning exposure to a random-contingency treatment is that it enables one to be sure that outcome-specific $\mathrm{S}-\mathrm{O}$ associations are being measured. 
The present study therefore used transfer tests to examine the impact of a random-contingency treatment upon previously learned $\mathrm{S}-\mathrm{O}$ associations. After acquiring differential $\mathrm{S}-\mathrm{O}$ associations, one group of rats was exposed to a random-contingency treatment and a second group of rats was exposed merely to a US-only treatment. Both groups were subsequently tested for the ability of the stimuli to transfer their control to instrumental responses on the basis of sharing outcomes with those responses. Inclusion of a US-only control group was thought necessary to determine the effect of postconditioning exposure to the degraded contingency per se. Such a control seems reasonable in light of the fact that very few studies have reported that postconditioning exposures only to the US has any deleterious effects upon conditioned performance (for a review, see Delamater \& LoLordo, 1991).

\section{Method}

\section{Subjects and Apparatus}

A new set of 16 male Sprague-Dawley rats, weighing $407-$ $512 \mathrm{~g}$ at the beginning of the experiment, were used. They were individually housed and maintained as in the previous experiments. The apparatus was the same as that used in the previous experiments.

\section{Procedure}

The procedures in the present study differed in several ways, as noted below, from those used in the previous experiments. These changes were made in order to accommodate random-contingency training. Initially, magazine and instrumental response training was administered as in the previous experiment.

Pavlovian acquisition. A Pavlovian conditioning procedure was implemented over the next 10 consecutive days. There were two sessions on each day separated by approximately $45 \mathrm{~min}$. One of these sessions involved conditioning of the $\mathrm{N}$ stimulus and the other involved conditioning of the L stimulus. Each 32-min session contained sixteen $30-\mathrm{sec}$ presentations of one of the stimuli. Reinforcements were presented during the stimuli according to a variable-time $30-\mathrm{sec}$ schedule of reinforcement. For half of the subjects, sucrose served as the US on $\mathrm{N}$ trials and pellets as the US on $L$ trials; the other rats received the reverse stimulus-reinforcer relations. Assignment of these stimulus-reinforcer relations was orthogonal to the earlier trained instrumental (leverpress and chainpull) response-reinforcer relations. The intertrial interval, measured from stimulus offset to the next onset, averaged $90 \mathrm{sec}$. Four event sequences differing in terms of the specific ITI values were repeated irregularly across training, and the order in which the stimuli received their conditioning sessions was balanced across days.

Postacquisition. Following the acquisition phase, the animals were assigned to two groups and run over 10 daily sessions. One of these, Group Random, was exposed to a random-contingency treatment. The random-contingency sessions were run exactly as the earlier acquisition sessions had been, with the exception that reinforcements were also presented during the ITI according to the same variable-time 30 -sec schedule of reinforcement as that used during the stimulus. The stimuli were treated in separate sessions, as in the acquisition phase, in order to avoid random pairings between a given stimulus and the outcome with which it was never trained.

The other group of rats, Group US-only, was treated exactly like Group Random with the exception that neither $\mathrm{N}$ nor $\mathrm{L}$ was presented in this phase.

Instrumental transfer tests. One transfer test was administered following the postacquisition phase. Two instrumental re- training sessions occurred on successive days, beginning on the day following the final postacquisition session. The transfer test occurred on the next day. This test was identical to that used in the previous experiment. Each stimulus was presented 16 times with an ITI of $30 \mathrm{sec}$, and no reinforcements were presented.

Following the first transfer test, the rats were given an additional 10 postacquisition sessions. Group Random received an additional 10 sessions of exposure to the random $\mathrm{S}-\mathrm{O}$ contingencies, and Group US-only received an additional 10 sessions of US-only presentations. After this second postacquisition cycle was completed, the rats were given two additional instrumental retraining sessions and then a second transfer test identical to the first.

\section{Results and Discussion}

Magazine responding in the acquisition and the postacquisition phases of the present experiment was not so readily interpretable, given the random nature of reinforcement delivery. Since reinforcement could have occurred at any moment during the stimulus, magazine responses measured during the stimulus could have reflected conditioned or unconditioned effects. No attempt was made in the present experiment to separate truly anticipatory magazine responding from reinforcer-evoked magazine responding. Therefore, magazine responses were not analyzed in the present experiment during the acquisition and postacquisition phases.

The data of greatest interest are from the transfer tests portrayed in Figure 5. Since a statistical analysis failed to reveal differences of any kind across the two test sessions, the data from both transfer tests have been combined. Equivalent outcome-selective transfer occurred in both groups. A split-plot ANOVA performed on these data revealed differences among same-outcome, differentoutcome, and pretrial response rates $[F(2,28)=9.86]$. Neither the group main effect nor the interaction between group and trial type approached statistical significance. Newman-Keuls post hoc tests revealed that same-

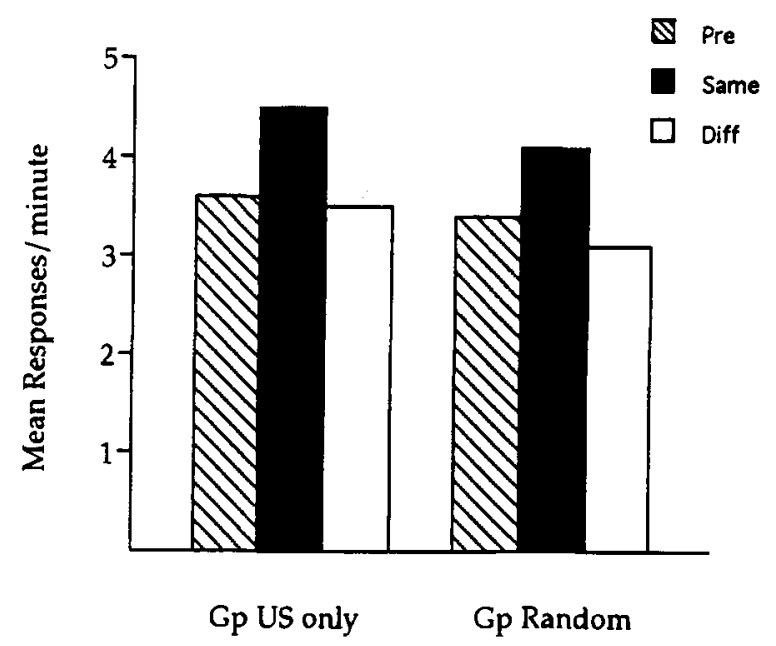

Figure 5. Mean instrumental responses per minute in the presence of and prior to the CSs during the transfer tests of Experiment 3 for the groups given postconditioning exposures to the US only or to a random relationship between CS and US. 
outcome responding was greater than different-outcome responding and pretrial responding in both groups.

A separate analysis was performed on the prestimulus response rates, separating pretrial same-outcome responses from pretrial different-outcome responses. Quite inexplicably, this analysis revealed an interaction between the factors of same/different response and group $[F(1,14)=$ 7.08]. Pretrial "same" and "different" responses for Group Random were 3.2 and 3.5 responses per minute, respectively. Those for Group US-only were 3.8 and 3.4, respectively. Because of this difference in pretrial responding, an additional split-plot ANOVA was performed on the CS data with pretrial response rates subtracted from CS response rates. This analysis was an attempt to "correct" for the between-groups difference seen in pretrial responding. After subtracting pretrial from trial responding, the same/difference effect was numerically larger in Group Random (same-difference $=0.9$ responses $/ \mathrm{min}-$ -0.4 responses $/ \mathrm{min}=1.3 \mathrm{responses} / \mathrm{min}$ ) than in Group US-only (same-difference $=0.7$ responses $/ \mathrm{min}-0.1$ responses $/ \mathrm{min}=0.6$ responses $/ \mathrm{min}$ ). However, as was true for the data depicted in Figure 5, the only significant effect in this analysis was that there were more same-outcome responses than different-outcome responses $[F(1,14)=$ 7.83]. The interaction with group was far from reliable.

The magazine data collected during the transfer tests are portrayed in Figure 6. This figure indicates that the groups differed in terms of the impact that the CS had upon ongoing magazine responding. A split-plot ANOVA indicated more magazine responding during the stimulus than in the prestimulus periods $[F(1,14)=28.02]$, but that this difference was larger in Group US-only $[F(1,14)=$ 6.02]. The main effect of group was also not reliable $[F(1,14)=1.47]$. Simple main effects tests (Kirk, 1968), performed in order to assess the source of the interaction, failed to reveal any between-group differences in pre-CS

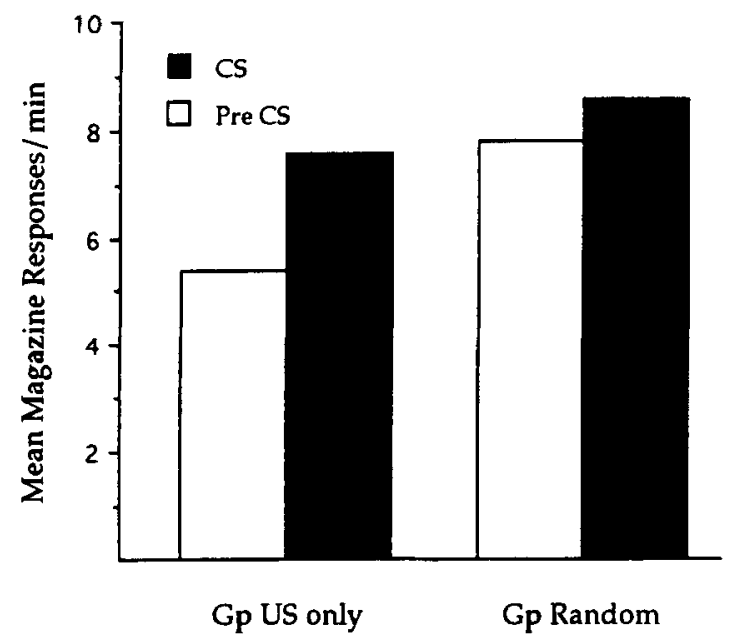

Figure 6. Mean magazine responses per minute prior to and in the presence of the CSs in Groups US-only and Random during the transfer tests of Experiment 3. or CS responding. Thus, all that can be claimed is that the difference between CS and pre-CS responding was larger in Group US-only. This interaction could mean that exposure to the random contingency had a deleterious effect upon conditioned magazine responses (see also Durlach \& Shane, 1994). However, this interpretation is complicated by the apparent lower level of pre-CS responding in Group US-only.

The data from the present experiment generally agree with those reported in the previous experiments in showing the resistance of $\mathrm{S}-\mathrm{O}$ associations to changes in the $\mathrm{S}-\mathrm{O}$ contingencies. In the present experiment, a change in the contingency was accomplished by randomizing the CS and US in time following conditioning. Although this procedure appeared to have some effect upon conditioned magazine responding to the stimuli, its effect upon outcome-selective transfer was no more severe than would be produced by a postconditioning US-only treatment. That the ability of the stimuli to show outcome-selective transfer was intact implies that the outcome-specific $\mathrm{S}-\mathrm{O}$ associations also survived these treatments.

In a sense, these data are also consistent with those obtained using test methods that are less specific in what aspect of the association they index (e.g., Durlach, 1986; Lindblom \& Jenkins, 1981; Rescorla, 1989). The conclusion derived from those studies was that postconditioning exposure to a random-contingency procedure has no impact upon previously established associations. The transfer data, here, also suggest this conclusion. They do so by going one step further in demonstrating that outcomespecific $\mathrm{S}-\mathrm{O}$ associations survive exposures to randomcontingency treatments.

\section{EXPERIMENT 4}

The previous experiment demonstrated an insensitivity of specific $\mathrm{S}-\mathrm{O}$ associations to a random-contingency treatment. The present experiment explored the effects of a more severe postconditioning-contingency manipulation on previously learned $\mathrm{S}-\mathrm{O}$ associations. A negativecontingency procedure in which the CS and US are explicitly unpaired (Eup) shares some features of both a simple extinction procedure (like that used in the first experiment) and a random-contingency procedure (like that used in the third experiment). In this procedure, the stimuli are nonreinforced, but at a time when reinforcement can also be presented during the intertrial interval.

Such a procedure may be viewed as more severe for several reasons. First, this procedure has been shown to result in a more rapid loss of conditioned responding than does a simple extinction procedure (e.g., Durlach, 1986; Lindblom \& Jenkins, 1981). Exposure to a postconditioning random contingency, in contrast, often results in either similar or less rapid loss of conditioned responding relative to a simple extinction procedure (e.g., Lindblom \& Jenkins, 1981). Second, on its own, this procedure has often been shown to result in the development of conditioned inhibition (e.g., see LoLordo \& Fairless, 
1985). Third, this procedure involves the conceptual opposite of original training.

Colwill (1993) has reported recently that $\mathrm{S}-\mathrm{O}$ associations learned during instrumental discrimination training can, in some sense, be undermined by a procedure that is the conceptual opposite of the original training procedure. For example, stimulus-control properties of an instrumental discriminative stimulus were reduced if the discriminative stimulus had been converted into an S-delta (for another response) signaling the omission of the original outcome. Interestingly, this effect was not obtained if the instrumental discriminative stimulus had been converted into a Pavlovian CS - using a negative-contingency procedure. It remains to be seen whether exposure to conceptually opposite Pavlovian $\mathrm{S}-\mathrm{O}$ contingencies might have similar deleterious effects upon these $\mathrm{S}-\mathrm{O}$ associations.

The present experiment was modeled after the previous experiment in addressing this question. The procedures were identical with one exception. In the present study, no reinforcements were presented during the stimuli in the negative-contingency phase.

Method
Subjects and Apparatus
A new set of 32 male Sprague-Dawley rats, weighing 534 -
743 g at the beginning of the experiment, were used. They were
individually housed and maintained as in the previous experi-
ments. The apparatus was the same as that used in the previous ex-
periments.
Procedure
The procedures used in the present study were identical to those
used in Experiment 3 , with one exception. In the postacquisition
phase, no reinforcements were presented during the 30 -sec stimu-
lus, nor were they presented during a 15 -sec period just prior to or
following the stimulus. Thus, all of the scheduled ITI USs were ex-
plicitly unpaired with the CS for Group Eup during the postacqui-
sition phase. Group US-only was treated exactly like Group Eup
except that neither N nor L was presented during these sessions.

\section{Results and Discussion}

As in the previous experiment, magazine responding during the acquisition and postacquisition phases was not analyzed.

The data of greatest interest are from the transfer tests, displayed in Figure 7. The data from both transfer tests have been combined because outcome-specific transfer was not observed to statistically interact with the factor of test session. Equivalent outcome-selective transfer occurred in both groups. A split-plot ANOVA performed on these data revealed a significant main effect only of trial type $[F(2,60)=21.97]$. Furthermore, although it appears as though more selective transfer may have occurred in Group US-only than in Group Eup, this interaction did not approach statistical significance $(F<1.00)$. In addition, overall response rates did not differ significantly between the groups.

To assess the nature of the trial-type main effect, Newman-Keuls post hoc tests performed on each group

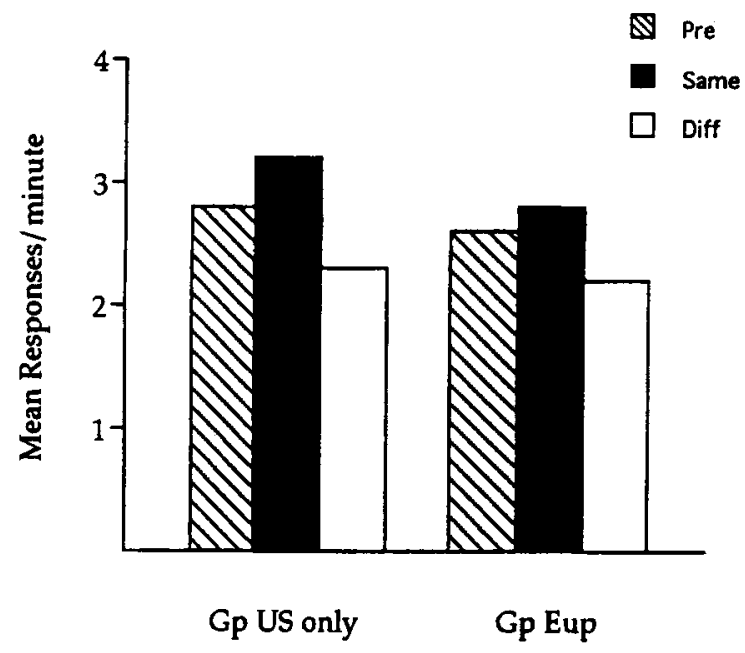

Figure 7. Mean instrumental responses per minute in the presence of and prior to the CSs during the transfer tests of Experiment 4 for the groups given postconditioning exposures to the US only or to an explicitly unpaired relationship between CS and US.

evaluated the possible paired comparisons between pretrial, same-outcome, and different-outcome responding. This analysis revealed that same-outcome responding was greater than different-outcome responding in each group. Same-outcome responding was also elevated relative to pretrial responding in Group US-only, but not in Group Eup. Finally, different-outcome responding was depressed relative to pretrial responding in both Group US-only and Group Eup.

The magazine data collected during the transfer tests are portrayed in Figure 8 . The data have been combined across both tests, but data from 1 subject in each group had to be excluded due to a problem with the magazine response-recording apparatus. This figure indicates that

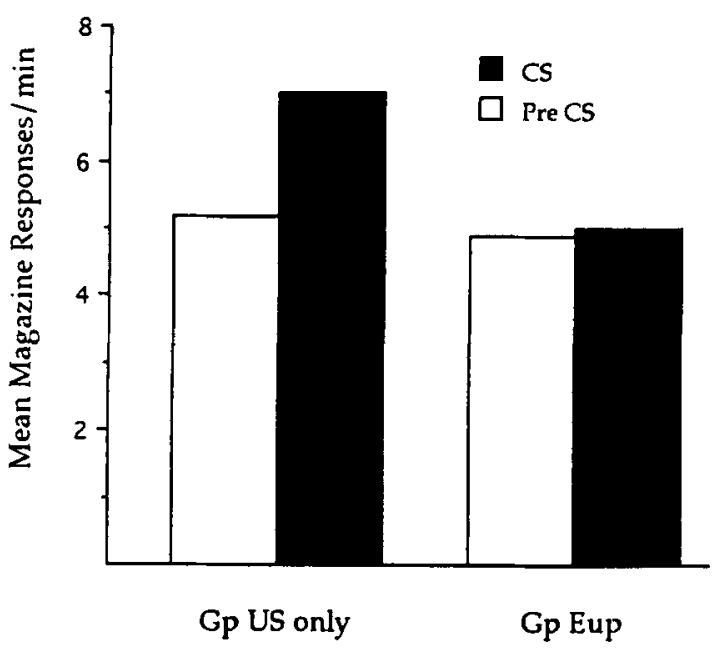

Figure 8. Mean magazine responses per minute prior to and in the presence of the CSs in Groups US-only and Eup during the transfer tests of Experiment 4. 
the groups differed in terms of the impact that the CS had upon ongoing magazine responding, as in the previous experiment. A split-plot ANOVA indicated that there was more magazine responding during the stimulus than in the prestimulus periods $[F(1,28)=14.72]$, but that this difference was larger in Group US-only $[F(1,28)=$ 12.32]. This interaction, also seen in the previous study, was not complicated by apparent between-group differences in pre-CS responding. Perhaps the larger sample size used in the present study was successful at minimizing the between-group variability seen in the previous study.

The data from the present experiment suggest that a rather extreme negative-contingency treatment has little, if any, impact upon the ability of stimuli to show outcomespecific transfer. The large sample size used in the present study $(n=16)$ suggests that if an effect of exposure to a negative contingency on outcome-specific transfer is to be found it is likely to be rather small.

Note, however, that in the present study the explicitly unpaired treatment, unlike the US-only treatment, reduced the ability of the stimuli to elevate responding over pretrial responding. One might take this as evidence of a harmful effect of the explicitly unpaired extinction procedure. It is worth noting that under the best of circumstances the elevation of instrumental responding by Pavlovian stimuli is by no means universally observed in transfer tests like those used here. Furthermore, the observation of an elevation of responding is not very informative about the status of the specific $\mathrm{S}-\mathrm{O}$ associations that mediate outcome-specific transfer. The difference between same-outcome and different-outcome responding is informative in this regard. Presently, it seems difficult to reject the conclusion that previously established S-O associations are no more affected by a negative-contingency treatment than they are by a US-only treatment.

The data were also clear in showing that, although transfer was largely unaffected by the contingency treatment, conditioned magazine responses were affected. Presumably, this reflects the presence of a decremental process acting directly upon the conditioned response. Moreover, since outcome-specific transfer was largely spared by the contingency treatment, this decremental process is not likely to be an outcome-specific one.

\section{GENERAL DISCUSSION}

The present experiments utilized the instrumental transfer test in demonstrating that $\mathrm{S}-\mathrm{O}$ associations acquired during Pavlovian training are highly resistant to changes brought about by procedures designed to undermine those associations. The first experiment documented this by using a simple extinction procedure; the second experiment did so with a procedure in which an alternative reinforcement replaced the original. This procedure is noteworthy since alternative reinforcement can be thought to ensure that stimuli are otherwise being processed at the time of nonreinforcement. The second experiment also demonstrated that the order in which multiple associations are established to a stimulus does not determine the strength of those associations. The final two experiments examined the impact of zero- and negative-contingency procedures upon previously learned $\mathrm{S}-\mathrm{O}$ associations. In neither of these studies was an effect upon $\mathrm{S}-\mathrm{O}$ associations apparent. In contrast to the repeated failures to observe an effect of these various treatments upon outcomespecific transfer, deleterious effects were often observed to occur upon conditioned magazine responses.

The findings of $\mathrm{S}-\mathrm{O}$ associations that survive various treatments designed to undermine those associations are consistent with results reported in other studies of Pavlovian extinction. Phenomena such as disinhibition, spontaneous recovery, renewal (Bouton \& Bolles, 1979), reinstatement (Rescorla \& Heth, 1975), and the recovery from zero- and negative-contingency response-elimination procedures (Lindblom \& Jenkins, 1981) all converge on the idea that a significant amount of learning survives these treatments. The present set of studies adds to these observations by demonstrating the seemingly complete immunity of $\mathrm{S}-\mathrm{O}$ associations that are specific in their representational content to various extinction treatments.

Several issues arise in connection with this conclusion. The first issue concerns the completeness of the effects reported in the present studies. Although no detectable effects of the various postconditioning treatments were observed in the present studies, it might be argued that decremental effects occurred equally in the various extinction and control conditions studied here. This possibility does not naturally apply to the results of the first experiment. However, the possibility of equal proactive and retroactive interference in the control and experimental groups, respectively, of Experiment 2 cannot be ruled out. Indeed, some researchers have noted a conceptual similarity between some proactive and retroactive interference effects (e.g., Bouton, 1991; Kraemer \& Spear, 1992). Resolution of this issue must await further research. In addition, it might be argued that, in Experiments 3 and 4, postconditioning exposures to the US alone had deleterious effects on prior conditioning which happened to equal that shown by the random- and negative-contingency groups. As mentioned previously, this is an unlikely result given the absence of such evidence in single-outcome studies (see, for a review, Delamater \& LoLordo, 1991).

Another issue concerns the sensitivity of the transfer test in gauging small differences in the strength of $\mathrm{S}-\mathrm{O}$ associations. It may be argued, for instance, that the transfer test requires only minimal levels of associative strength for selective effects to be observed. Perhaps the manipulations used here did not totally eliminate associative strength. Although this argument cannot be easily dismissed on the basis of any of the data presented here, data reported elsewhere are relevant. Delamater (1995) recently has observed different amounts of transfer displayed by stimuli that may be presumed to differ in associative strength. In one experiment, differential outcome training to two stimuli $\left(\mathrm{A}+\right.$ and $\left.\mathrm{B}^{*}\right)$ was followed by a 
procedure in which one of the outcomes was also presented in the intertrial interval (e.g., $\mathrm{A}+,+, \mathrm{B}^{*}$ ). This treatment resulted in more outcome-specific transfer of $B$ than of $A$. This result demonstrates that the transfer test can be sensitive to presumed differences in associative strength between stimuli.

While this result indicates the sensitivity of the transfer test, there is a sense in which the finding of outcomespecific effects of intertrial reinforcement (Delamater, 1995) are inconsistent with the data reported in Experiments 3 and 4 of the present study. This discrepancy is currently not well understood. However, it may be noted that one potentially important procedural difference between these two sets of studies is that in the present experiments, both CS-US contingencies were degraded concurrently. Delamater (1995) degraded only one CSUS contingency while maintaining a second highly positive (i.e., $\mathrm{A}+,+, \mathrm{B}^{*},{ }^{*}$ vs. $\mathrm{A}+,+, \mathrm{B}^{*}$ ). Others (e.g., Jenkins, 1984) have noted that contrasting conditions of reinforcement and nonreinforcement may play a critical role in learning.

Another issue arising from the present series of experiments concerns the question of whether Pavlovian conditioning is really being examined in the present studies. Given that a magazine response is required for the rat to consume the reinforcer, this response contingency might make the paradigm more appropriately described as a discriminated instrumental paradigm than a Pavlovian one. This issue is probably unresolvable. Although some researchers have taken magazine approach as Pavlovian in nature (see Balleine \& Dickinson, 1991), perhaps the best one can do is to construct a situation in which instrumental contingencies differ in their complexity (see Rescorla, 1994a). Compared with most traditional instrumental procedures, rather minimal response requirements were imposed in the present experiments. At the very least, then, the present experiments document the strong resistance of $\mathrm{S}-\mathrm{O}$ associations even in situations involving minimal response contingencies. Referring to these $\mathrm{S}-\mathrm{O}$ associations as Pavlovian underscores this feature of the procedures.

The strong resistance of these $\mathrm{S}-\mathrm{O}$ associations is similar to that shown in more complex instrumental conditioning settings. Each of the manipulations used in the present studies, or variants of them, have also been used to explore the durability of instrumental $\mathrm{S}-\mathrm{O}$ or $\mathrm{R}-\mathrm{O}$ associations. The overall pattern of results in the two separate investigations is very similar. This parallel set of observations may reflect a basic similarity in the associative processes of Pavlovian and instrumental conditioning (also see Mackintosh, 1983).

An observation of Colwill's (1993), however, challenges this view. Colwill noted that control by an instrumental discriminative stimulus could be undermined if the stimulus was converted into an instrumental S-delta but not if it was converted into a Pavlovian CS- . A particularly strong case for separate instrumental and Pavlovian processes could be made if the converse were also true- - that is, if a CS + could be undermined more effectively by conversion into a $\mathrm{CS}-$ than by conversion into an instrumental S-delta. The data from the final experiment reported here, however, failed to find an effect of Pavlovian negative-contingency training on prior excitatory Pavlovian conditioning. One way to interpret the results from both Colwill's experiments and Experiment 4 here is to assume that a Pavlovian CS - procedure might generally be less effective than an instrumental S-delta procedure at generating a form of associative inhibition (see, also, Colwill, 1993). This suggests that conversion of a CS + into an instrumental S-delta might also be more effective than conversion into a CS-.

The present data also have implications for an understanding of extinction. Two presently popular accounts of extinction involve changes in stimulus or memory processes. According to the former (e.g., see Robbins, 1990), a loss in conditioned responding reflects a loss in the degree to which stimuli are attended to and processed. This mechanism might be seen as providing an associative structure with a means for protecting itself against the deleterious effects of nonreinforcement. Associations cannot undergo decrements if elements of the association are not processed. It follows from this reasoning, however, that a procedure that encouraged continued processing of the stimulus during extinction would have harmful effects on the association. The results from the final three experiments reported here did not provide empirical support for this hypothesis. In the second experiment, training with an alternative reinforcer should have been especially effective at maintaining stimulus processing during nonreinforcement of the original outcomes. Moreover, in conceptually similar studies, Bouton and Peck (1992; also Peck \& Bouton, 1990) also observed significant retention of originally trained associations following a treatment that should have encouraged stimulus processing during the nonreinforcement phase. In these studies, Phase 2 training was with an alternative outcome that had opposing motivational value (e.g., food and shock), and recovery of Phase 1 conditioned responding was observed to accompany physical or temporal context shifts. Furthermore, in the final two experiments reported here the presence of reinforcements in the intertrial interval might have been considered a manipulation that should have maintained stimulus processing. A final problem faced by this account is the effect of extinction and contingency treatments upon magazine responses but not transfer.

A memory-based account of extinction assumes that animals separately learn to represent memories of acquisition and extinction (see, e.g., Bouton, 1991). During a test, the response will reflect whichever of these two memories is most well retrieved. For such an account to apply here, some assumptions would be required as to why the acquisition memories dominated during the transfer tests. It might be assumed, for example, that the presence of reinforcement during instrumental retraining sessions "reinstated" the acquisition memories (Rescorla 
\& Heth, 1975). Another retrieval mechanism would be demanded, however, by the results of the final two contingency experiments. In those studies, reinforcements could just as easily have reinstated memories from the zero- and negative-contingency phases (Bouton, Rosengard, Achenbach, Peck, \& Brooks, 1993). Alternatively, it might be assumed that transfer testing constituted a type of context change. This context change, in turn, could have allowed for a renewal of the originally trained associations (Bouton \& Ricker, 1994). A general problem facing these sorts of accounts concerns the different effects of the various treatments used here upon conditioned magazine behaviors and transfer. Some allowance for specific response sensitivity differences would have to be specified.

Another way of conceptualizing extinction is in terms of response-specific inhibitory processes (e.g., see Rescorla, 1993). One such process, which appears to have been observed in other procedures (e.g., Bonardi, 1989; Colwill, 1991), entails the establishment of direct inhibitory S-R associations. Such associations could form in parallel to already acquired $\mathrm{S}-\mathrm{O}$ associations. An obvious consequence from such a view is that the effects of extinction upon stimulus control should be response specific. Furthermore, if the only effect of extinction was to generate parallel inhibitory $S-R$ associations, then the ability of stimuli to use their $\mathrm{S}-\mathrm{O}$ associations during a transfer test should be fully intact. It is noteworthy that in the present studies extinction appeared to have enduring effects on conditioned magazine responses, while at the same time sparing the integrity of the $\mathrm{S}-\mathrm{O}$ associations.

Yet another way of viewing extinction, suggested by an anonomous reviewer, also may allow for the dissociation between conditioned magazine responding and transfer seen in the present studies. On the basis of the ideas from Dickinson and Dearing (1979), one might argue that extinction arises from the conditioning of a motivational state opposed to that evoked by the reinforcer rather than an unlearning of the specific $\mathrm{S}-\mathrm{O}$ association that mediates transfer. If conditioned responding depends upon appetitive motivation but outcome-selective transfer does not, then one should expect the sort of dissociation observed here. This framework makes sense of the fact that in some situations outcome-specific transfer can occur even when the outcome has been devalued (Rescorla, 1994b). Furthermore, with this account, one might expect to observe a general depressive effect of extinction upon both same-outcome and different-outcome responses during transfer tests. Although this general depression has not been observed to occur statistically in the present studies, it is noteworthy that this tendency has often been observed here and in many of the studies reported by Rescorla.

Regardless of how one interprets the nature of extinction, the results presented here strengthen the belief that specific Pavlovian $\mathrm{S}-\mathrm{O}$ associations, once acquired, are rather insensitive to a host of manipulations designed to undermine those associations. Such results serve to ex- tend the range of conditions under which the durability of $\mathrm{S}-\mathrm{O}$ associations has been observed.

\section{REFERENCES}

BaLleine, B., \& Dickinson, A. (1991). Instrumental performance following reinforcer devaluation depends upon incentive learning. Quarterly Journal of Experimental Psychology, 43B, 279-296.

BoNARDI, C. (1989). Inhibitory discriminative control is specific to both the response and the reinforcer. Quarterly Journal of Experimental Psychology, 41 B, 225-242.

Bouton, M. E. (1991). Context and retrieval in extinction and in other examples of interference in simple associative learning. In L. W. Dachowski \& C. F. Flaherty (Eds.), Current topics in animal learning: Brain, emotion, and cognition (pp. 25-53). Hillsdale, NJ: Erlbaum.

Bouton, M. E., \& Bolles, R. C. (1979). Role of conditioned contextual stimuli in reinstatement of extinguished fear. Journal of Experimental Psychology: Animal Behavior Processes, 5, 368-378.

Bouton, M. E., \& PECK, C. A. (1992). Spontaneous recovery in crossmotivational transfer (counterconditioning). Animal Learning \& Behavior, 20, 313-321.

Bouton, M. E., \& RiCKer, S. T. (1994). Renewal of extinguished responding in a second context. Animal Learning \& Behavior, 22, 317-324.

Bouton, M. E., Rosengard, C., Achenbach, G. G., Peck, C. A., \& BRoOKs, D.C. (1993). Effects of contextual conditioning and unconditional stimulus presentation on performance in appetitive conditioning. Quarterly Journal of Experimental Psychology, 46B, 63-95.

Colwill, R. M. (1991). Negative discriminative stimuli provide information about the identity of omitted response-contingent outcomes. Animal Learning \& Behavior, 19, 326-336.

CoLWILL, R. M. (1993). Signaling the omission of a response-contingent outcome reduces discriminative control. Animal Learning \& Behavior, 21, 337-345.

Colwill, R. M. (1994). Associative representations of instrumental contingencies. In D. L. Medin (Ed.), The psychology of learning and motivation (Vol. 28, pp. 1-72). New York: Academic Press.

Colwill, R. M., \& Rescorla, R. A. (1988). Associations between the discriminative stimulus and the reinforcer in instrumental learning. Journal of Experimental Psychology: Animal Behavior Processes, 14, 155-164.

Delamater, A. R. (1995). Outcome-selective effects of intertrial reinforcement in a Pavlovian appetitive conditioning paradigm with rats. Animal Learning \& Behavior, 23, 31-39.

Delamater, A. R., \& LoLordo, V. M. (1991). Event revaluation procedures and associative structures in Pavlovian conditioning. In L. Dachowski \& C. F. Flaherty (Eds.), Current topics in animal learning: Brain, emotion, and cognition (pp. 55-94). Hillsdale, $\mathrm{NJ}$ : Erlbaum.

Dickinson, A., \& Dearing, M. F. (1979). Appetitive-aversive interactions and inhibitory processes. In A. Dickinson \& R. A. Boakes (Eds.), Mechanisms of learning and motivation: A memorial volume to Jerzy Konorski (pp. 203-231). Hillsdale, NJ: Erlbaum.

Durlach, P. J. (1986). Explicitly unpaired procedure as a response elimination technique in autoshaping. Journal of Experimental Psychology: Animal Behavior Processes, 12, 172-185.

Durlach, P. J., \& Shane, D. O. (1993). The effect of intertrial food presentations on anticipatory goal-tracking in the rat. Quarterly Journal of Experimental Psychology, 46B, 289-318.

FARWELl, B. J., \& AYRES, J. J. (1979). Stimulus reinforcer and response reinforcer relations in the control of conditioned appetitive headpoking (goal tracking) in rats. Learning \& Motivation, 10, 295312.

GibBon, J., \& Balsam, P. (1981). Spreading association in time. In C. M. Locurto, H. S. Terrace, \& J. Gibbon (Eds.), Autoshaping and conditioning theory (pp. 219-253). New York: Academic Press.

Holland, P. C. (1979). Differential effects of omission contingencies on various components of Pavlovian appetitive conditioned responding in rats. Journal of Experimental Psychology: Animal Behavior Processes, 5, 178-193. 
Holland, P. C., \& Rescorla, R. A. (1975). The effect of two ways of devaluing the unconditioned stimulus after first- and second-order appetitive conditioning. Journal of Experimental Psychology: Animal Behavior Processes, 1, 355-363.

JENKINS, H. M. (1984). Time and contingency in classical conditioning. In J. Gibbon \& L. Allan (Eds.), Timing and time perception (Annals of the New York Academy of Sciences, Vol. 423, pp. 242253). New York: New York Academy of Sciences.

KIRK, R. E. (1968). Experimental design: Procedures for the behavioral sciences. Belmont, CA: Brooks/Cole.

Kraemer, P. J., \& SPEAR, N. E. (1992). The effect of nonreinforced stimulus exposure on the strength of a conditioned taste aversion as a function of retention interval: Do latent inhibition and extinction involve a shared process? Animal Learning \& Behavior, 20, 1-7.

Kruse, J. M., Overmier, J. B., Konz, W. A., \& RokKe, E. (1983). Pavlovian conditioned stimulus effects upon instrumental choice behavior are reinforcer specific. Learning \& Motivation, 14, 165-181.

LiNDBLOM, L. L., \& JeNKINS, H. M. (1981). Responses eliminated by noncontingent or negatively contingent reinforcement recover in extinction. Journal of Experimental Psychology: Animal Behavior Processes, 7, 175-190.

LoLoRdo, V. M., \& FAIRless, J. L. (1985). Pavlovian conditioned inhibition: The literature since 1969. In R. R. Miller \& N. E. Spear (Eds.), Information processing in animals: Conditioned inhibition (pp. 1-49). Hillsdale, NJ: Erlbaum.

Mackintosh, N. J. (1983). Conditioning and associative learning. New York: Oxford University Press.

PECK, C. A., \& Bouton, M. E. (1990). Context and performance in aversive-to-appetitive and appetitive-to-aversive transfer. Learning \& Motivation, 21, 1-31.

ResCORLA, R. A. (1967). Pavlovian conditioning and its proper control procedures. Psychological Review, 74, 71-80.
ResCorla, R. A. (1989). Redundant treatments of neutral and excitatory stimuli in autoshaping. Journal of Experimental Psychology: Animal Behavior Processes, 15, 212-222.

RESCORLA, R. A. (1991). Associations of multiple outcomes with an instrumental response. Journal of Experimental Psychology: Animal Behavior Processes, 17, 465-474.

Rescorla, R. A. (1992a). Associations between an instrumental discriminative stimulus and multiple outcomes. Journal of Experimental Psychology: Animal Behavior Processes, 18, 95-104.

Rescorla, R. A. (1992b). Response-independent outcome presentation can leave instrumental R-O associations intact. Animal Learning \& Behavior, 20, 104-111.

ResCoRLA, R. A. (1993). Inhibitory associations between $S$ and $R$ in extinction. Animal Learning \& Behavior, 21, 327-336.

Rescorla, R. A. (1994a). Control of instrumental performance by Pavlovian and instrumental stimuli. Journal of Experimental Psychology: Animal Behavior Processes, 20, 44-50.

REsCORLA, R. A. (1994b). Transfer of instrumental control mediated by a devalued outcome, Animal Learning \& Behavior, 22, 27-33.

ResCorla, R. A., \& Heth, C. D. (1975). Reinstatement of fear to an extinguished conditioned stimulus. Journal of Experimental Psychology: Animal Behavior Processes, 1, 88-96.

RESCORLA, R. A., \& WAGNeR, A. R. (1972). A theory of Pavlovian conditioning: Variations in the effectiveness of reinforcement and nonreinforcement. In A. Black \& W. F. Prokasy (Eds.), Classical conditioning $I I$ (pp. 64-99). New York: Appleton-Century-Crofts.

Robiins, S. J. (1990). Mechanisms underlying spontaneous recovery in autoshaping. Journal of Experimental Psychology: Animal Behavior Processes, 16, 235-249.

(Manuscript received July 7, 1995;

revision accepted for publication February 2, 1996.) 